\title{
A novel polyhedral oligomeric silsesquioxane-modified layered double hydroxide: preparation, characterization and properties
}

\author{
Xianwei Zhang ${ }^{1}$, Zhongzhu Ma ${ }^{1}$, Hong Fan ${ }^{*}$, Carla Bittencourt ${ }^{\star 2}$, Jintao Wan ${ }^{*}$ \\ and Philippe Dubois ${ }^{2}$
}

\author{
Full Research Paper \\ Address: \\ ${ }^{1}$ State Key Laboratory of Chemical Engineering, College of Chemical \\ and Biological Engineering, Zhejiang University, Hangzhou 310027, \\ China, ${ }^{2}$ Center of Innovation and Research in Materials and Polymers \\ (CIRMAP), University of Mons, Place du Parc 23, B-7000 Mons, \\ Belgium and ${ }^{3}$ School of Materials Science and Engineering, Shaanxi \\ Normal University, Xi'an 710119, China

\section{Email:} \\ Hong Fan* - hfan@zju.edu.cn; Carla Bittencourt ${ }^{*}$ - \\ carla.bittencourt@umons.ac.be; Jintao Wan* - \\ d05wanjintao@zju.edu.cn \\ * Corresponding author \\ Keywords: \\ flammability; layered double hydroxide; polyhedral oligomeric \\ silsesquioxane; thermal stability \\ Beilstein J. Nanotechnol. 2018, 9, 3053-3068. \\ doi:10.3762/bjnano.9.284 \\ Received: 10 May 2018 \\ Accepted: 25 November 2018 \\ Published: 19 December 2018 \\ Associate Editor: P. Leiderer \\ (c) 2018 Zhang et al.; licensee Beilstein-Institut. \\ License and terms: see end of document.
}

\begin{abstract}
A novel layered double hydroxide modified by octa-substituted carboxy-terminated polyhedral oligomeric silsesquioxane was prepared via a one-step method and characterized by Fourier-transform infrared spectroscopy, X-ray photoelectron spectroscopy, $\mathrm{X}$-ray diffraction, transmission electron microscopy, scanning electron microscopy, elemental analysis, thermogravimetric analysis, and microscale combustion calorimetry (MCC). Results showed that the silsesquioxane modified-LDH (OLDH) revealed an increase in the interlayer distance, nanoscale plate-like morphology of primary particles, and improved thermal stability. A synergistic effect between the siloxane moiety and $\mathrm{Mg}-\mathrm{Al}$ hydroxide was found during thermal degradation, and confirmed by the study of degradation kinetics together with the analysis of the surface morphologies and elemental components of char residues. Moreover, in contrast to conventional organic modified LDH (e.g., dodecylbenzenesulfonate-LDH), the MCC results showed a significant decrease in the heat release rate and total heat release, indicating the low flammability of OLDH.
\end{abstract}

\section{Introduction}

Layered double hydroxides (LDHs) are typical host-guest materials, with unique lamellar structures composed of positively charged brucite-like layers and an interlayer region containing charge compensating anions and solvate molecules. The metal cations are octahedrally surrounded by hydroxide ions, and the octahedra units share their edges connecting to form infinite $2 \mathrm{D}$ 
sheets [1]. $\left[\mathrm{M}^{2+}{ }_{1-x} \mathrm{M}^{3+}{ }_{x}(\mathrm{OH})_{2}\right]^{x+} \cdot \mathrm{A}^{n-}{ }_{x / n} \cdot y \mathrm{H}_{2} \mathrm{O}$ is the generic structural formula for LDHs, where $\mathrm{M}^{2+}, \mathrm{M}^{3+}$ and $\mathrm{A}^{n-}$ represent divalent metal cations (e.g., $\mathrm{Mg}^{2+}, \mathrm{Zn}^{2+}, \mathrm{Ni}^{2+}, \mathrm{Co}^{2+}$ ), trivalent metal cations (e.g., $\mathrm{Al}^{3+}, \mathrm{Fe}^{3+}, \mathrm{Mn}^{3+}, \mathrm{Cr}^{3+}$ ) and interlayer anions (e.g., $\mathrm{NO}_{3}{ }^{-}, \mathrm{Cl}^{-}, \mathrm{CO}_{3}{ }^{2-}$ ), respectively [2,3]. The stoichiometric coefficient $x$ is typically in the range of $0.17-0.33$, and the species of metallic ions and intercalated anions are variable, giving rise to versatile isostructural LDHs [1-4].

In recent years, LDHs have found wide application in polymer nanocomposites because they are highly tunable and can observably improve the flame retardancy of polymers [5-13]. Due to size effects, the strong hydrophilicity and the strong affinity between the hydroxide layers, LDHs are difficult to homogeneously and stably disperse in polymer matrices. Therefore organic modification of LDHs is essential before using them as nanofillers. So far, many organic modifiers have been successfully used to modify LDHs. One of the most commonly used is sodium dodecylbenzene sulfonate (SDBS) [7,14]. Other modifiers include a variety of sulfate and phosphate surfactants [15-17], aliphatic and aromatic mono- and dicarboxylic acids $[18,19]$, amino acids [20], anionic dyes [11], and compounds of biological origin, such as $\beta$-cyclodextrin and eugenol derivatives $[9,10,13,21]$. However, most of these current modifiers do not have satisfactory thermal stability and are flammable, reducing the thermal and fire stability of the LDHs after modification, which is expected to eventually limit the potential for applications of LDHs in polymer composites.

Polyhedral oligomeric silsesquioxanes (POSS) are a class of well-defined nanostructured molecules, which contain a silica cage core and externally attached organic substituents [22]. These 3D nanoclusters follow the basic composition formula of $\mathrm{R}_{n}\left(\mathrm{SiO}_{1.5}\right)_{n}$ and have a size of 1 to $3 \mathrm{~nm}$ in diameter when the vertex groups $(\mathrm{R})$ are included. The siloxane cage in POSS provides the thermally and chemically robust framework, while the organic functionality can be chemically modified in a controlled manner, making POSS a class of promising nanoscale building blocks for advanced functional nanomaterials [22-24]. Besides, the unique inorganic-organic architecture also endows POSS with low dielectric constant, high thermal and oxidation resistance $[23,25]$. And unlike traditional organic compounds, POSS chemicals are odorless and environmentally friendly as they release no volatile organic components. There are reports about the successful introduction of acid groups such as - $\mathrm{COOH}$ in POSS structures [26,27], making it possible to use POSS as ionic intercalators. However, there is scarcely any report on the use of POSS to intercalate LDHs.

Aiming to develop an organically modified LDH with satisfactory thermal stability and low flammability, an octa-substituted carboxy-terminated polyhedral oligomeric silsesquioxane (OCPS, Figure 1) was synthesized and originally employed to modify $\mathrm{Mg}-\mathrm{Al} \mathrm{LDH}$ in this work. Herein, OCPS was chosen as the candidate POSS intercalator because of the following advantages: (i) The long alkyl chains anchoring on the rigid POSS cage are flexible, reducing the resistance against the formation of layered structure. (ii) The OCPS molecule is rich in carboxylate groups, which could counterbalance multiple positive sheet charges. (iii) The high hydrocarbon content of the intercalator is helpful in improving the affinity of LDH to carbon-based materials. The OPCS-modified LDH (OLDH) was designed and prepared using a one-step route, followed by the systematical investigation of its structure, morphology, thermal stability and combustion behavior. It was expected that the incorporation of the POSS moiety into LDH structure would result in good maintenance of thermal stability and improved fire resistance than traditional organically modified LDHs, e.g., DBS-LDH.

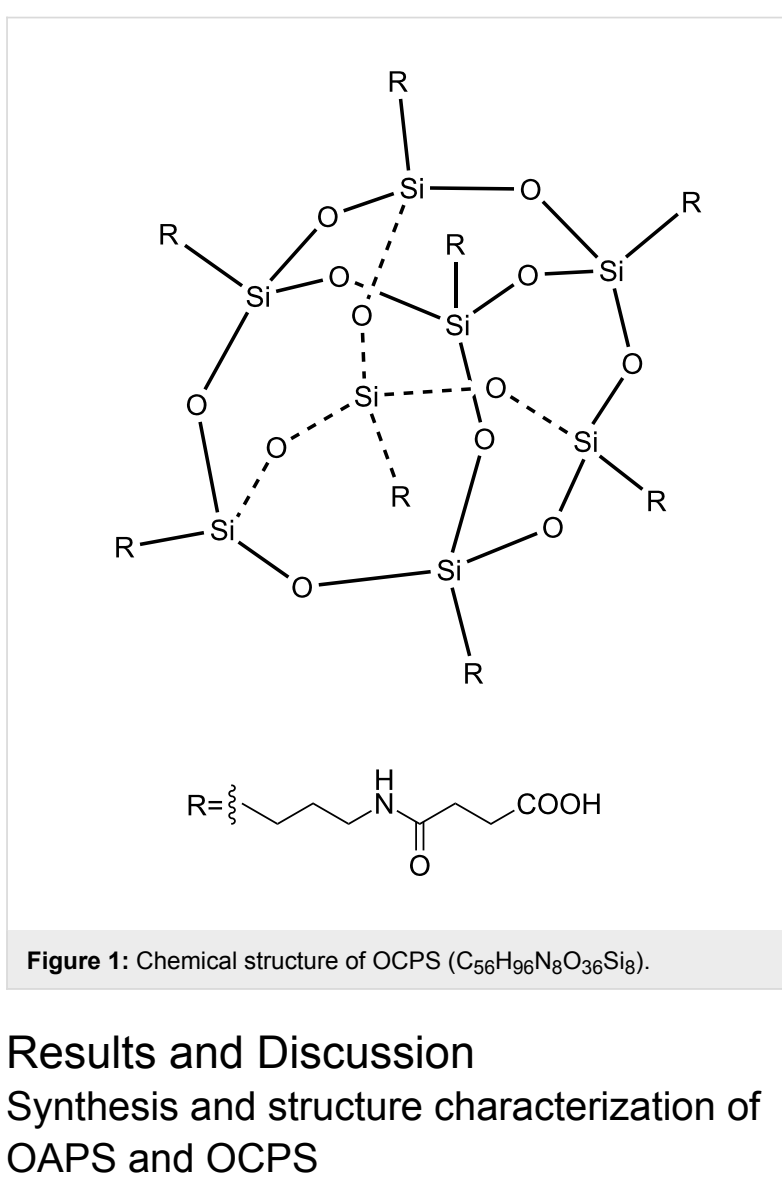

The route for the synthesis of octa-substituted carboxyterminated POSS (OCPS) is depicted in Scheme 1. First, octa-ammonium POSS (OAPS) was synthesized employing a modified refluxing method [28-30]. Thereafter, the acylation reaction of OCPS with succinic anhydride was carried out to afford OCPS. 


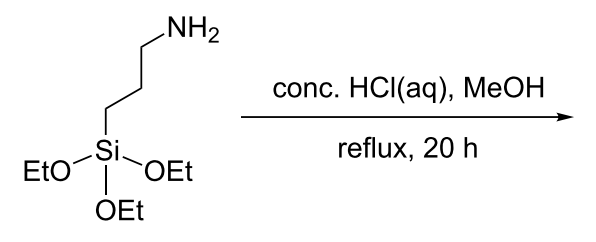

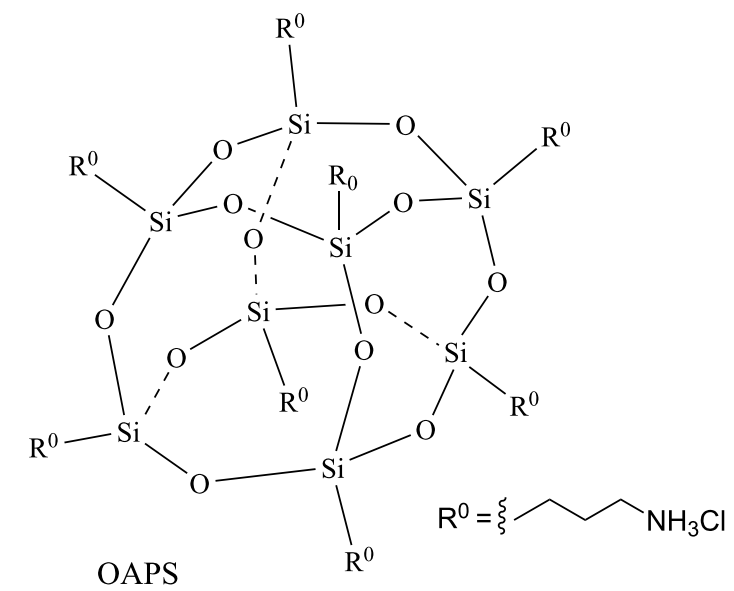<smiles>O=C1CCC(=O)O1</smiles><smiles>[R][R]1([R])O[Si]2([R])O[Si]3([R])O[Si]4([R])O[Si]([R])(O1)O[Si]1([R])O[Si]([R])(O2)O[Si]([R])(O3)O[Si]([R])(O4)O1</smiles>

Scheme 1: Synthesis of OCPS.

The ${ }^{1} \mathrm{H}$ NMR, ${ }^{13} \mathrm{C}$ NMR and ${ }^{29} \mathrm{Si}$ NMR spectra of OAPS and OCPS presented in Figure 2 and the MALDI-TOF-MS spectra, XRD patterns and FTIR spectra of OAPS and OCPS in Figure $3 \mathrm{a}-\mathrm{c}$ reveal the well-defined structures. The SEM images of OCPS in Figure 3d show that OCPS has a micrometer-sized strip geometry. The details are as follows: (1) for OAPS: ${ }^{1} \mathrm{H}$ NMR (DMSO- $\left.d_{6}\right) \delta 8.27\left(\mathrm{~s}, \mathrm{NH}_{3}, 24 \mathrm{H}\right), 2.78$ (s, $\left.\mathrm{CH}_{2} \mathrm{~N}, 16 \mathrm{H}\right), 1.73$ (s, $\left.\mathrm{SiCH}_{2} \mathrm{CH}_{2}, 16 \mathrm{H}\right), 0.69$ (m, $\left.\mathrm{SiCH}_{2}, 16 \mathrm{H}\right)$; ${ }^{1} \mathrm{H}$ NMR $\left(\mathrm{D}_{2} \mathrm{O}\right) \delta 2.96\left(\mathrm{~m}, \mathrm{CH}_{2} \mathrm{~N}, 16 \mathrm{H}\right), 1.73\left(\mathrm{~m}, \mathrm{SiCH}_{2} \mathrm{CH}_{2}\right.$, $16 \mathrm{H}), 0.70\left(\mathrm{~m}, \mathrm{SiCH}_{2}, 16 \mathrm{H}\right) ;{ }^{13} \mathrm{C}$ NMR (DMSO- $\left.d_{6}\right) \delta 41.03(\mathrm{~s}$, $\left.\mathrm{CH}_{2} \mathrm{~N}\right), 20.64\left(\mathrm{~s}, \mathrm{SiCH}_{2} \mathrm{CH}_{2}\right), 8.46\left(\mathrm{~s}, \mathrm{SiCH}_{2}\right) ;{ }^{13} \mathrm{C} \mathrm{NMR}\left(\mathrm{D}_{2} \mathrm{O}\right)$ $\delta 41.63\left(\mathrm{~d}, \mathrm{CH}_{2} \mathrm{~N}\right), 20.55\left(\mathrm{~d}, \mathrm{SiCH}_{2} \mathrm{CH}_{2}\right), 8.76\left(\mathrm{~m}, \mathrm{SiCH}_{2}\right)$; ${ }^{29} \mathrm{Si}$ NMR (DMSO- $\left.d_{6}\right) \delta-66.50(\mathrm{~s})$; MALDI-TOF-MS (DHB matrix, $\mathrm{m} / z):[\mathrm{M}+\mathrm{H}-8 \mathrm{HCl}]^{+}$calcd 881.29 ; found, 881.39 $(100 \%)$; FTIR (KBr): v $\left(-\mathrm{NH}_{3}{ }^{+}\right) 3200-2800 \mathrm{~cm}^{-1}, \delta_{\mathrm{as}}\left(-\mathrm{NH}_{3}{ }^{+}\right)$
$1606 \mathrm{~cm}^{-1}, v(\mathrm{Si}-\mathrm{O}-\mathrm{Si}) 1175-1060 \mathrm{~cm}^{-1}, \mathrm{v}(\mathrm{Si}-\mathrm{C}) 800 \mathrm{~cm}^{-1}$; XRD: $2 \theta 6.72^{\circ}, 7.32^{\circ}, 11.00^{\circ}, 18.55^{\circ}, 20.34^{\circ}, 22.03^{\circ}, 23.01^{\circ}$, $25.57^{\circ}$. (2) for OCPS: ${ }^{1} \mathrm{H}$ NMR (DMSO- $\left.d_{6}\right) \delta 11.95(\mathrm{~s}, \mathrm{br}$, $\mathrm{COOH}, 8 \mathrm{H}), 7.83(\mathrm{t}, J=4.9 \mathrm{~Hz}, \mathrm{NHC}=\mathrm{O}, 8 \mathrm{H}), 3.00(\mathrm{~d}$, $\left.J=5.3 \mathrm{~Hz}, \mathrm{CH}_{2} \mathrm{~N}, 16 \mathrm{H}\right), 2.41\left(\mathrm{t}, J=6.6 \mathrm{~Hz}, \mathrm{CH}_{2} \mathrm{COOH}, 16 \mathrm{H}\right)$, 2.30 (t, $\left.J=6.5 \mathrm{~Hz}, \mathrm{C}=\mathrm{OCH}_{2}, 16 \mathrm{H}\right), 1.43\left(\mathrm{~s}, \mathrm{CH}_{2} \mathrm{CH}_{2} \mathrm{CH}_{2}\right.$, $16 \mathrm{H}), 0.59\left(\mathrm{~s}, \mathrm{SiCH}_{2}, 16 \mathrm{H}\right) ;{ }^{13} \mathrm{C} \mathrm{NMR}\left(\mathrm{DMSO}-d_{6}\right) \delta 174.11(\mathrm{~s}$, $\mathrm{COOH}$ ), 171.24 (s, NHCO), $41.20\left(\mathrm{~s}, \mathrm{CH}_{2} \mathrm{CH}_{2} \mathrm{CH}_{2}\right), 30.18$ (s, $\mathrm{CH}_{2} \mathrm{NH}$ ), 29.33 (s, $\left.\mathrm{CH}_{2} \mathrm{COOH}\right), 22.67$ (s, $\mathrm{C}=\mathrm{OCH}_{2}$ ), 8.92 (s, $\mathrm{SiCH}_{2}$ ); ${ }^{29} \mathrm{Si}$ NMR (DMSO- $\left.d_{6}\right) \delta-66.19$ (s); MALDI-TOF-MS (DHB matrix, $m / z$ ): $[\mathrm{M}+\mathrm{H}]^{+}$calcd 1681.42 , found 1681.72 ; $[\mathrm{M}+\mathrm{Na}]^{+}$calcd 1703.70; found, 1704.70; $[\mathrm{M}+\mathrm{K}]^{+}$calcd 1719.37; found, 1719.67; FTIR (KBr): v(-COOH) $3300 \mathrm{~cm}^{-1}$, $\delta(-\mathrm{COOH}) 1432 \mathrm{~cm}^{-1}, \mathrm{v}(-\mathrm{COOH}) 1701 \mathrm{~cm}^{-1}, \mathrm{v}(-\mathrm{NHC}=O)$ $1645 \mathrm{~cm}^{-1}, v(\mathrm{Si}-\mathrm{O}-\mathrm{Si}) 1150-1110 \mathrm{~cm}^{-1}, v(\mathrm{Si}-\mathrm{C}) 800 \mathrm{~cm}^{-1}$; 

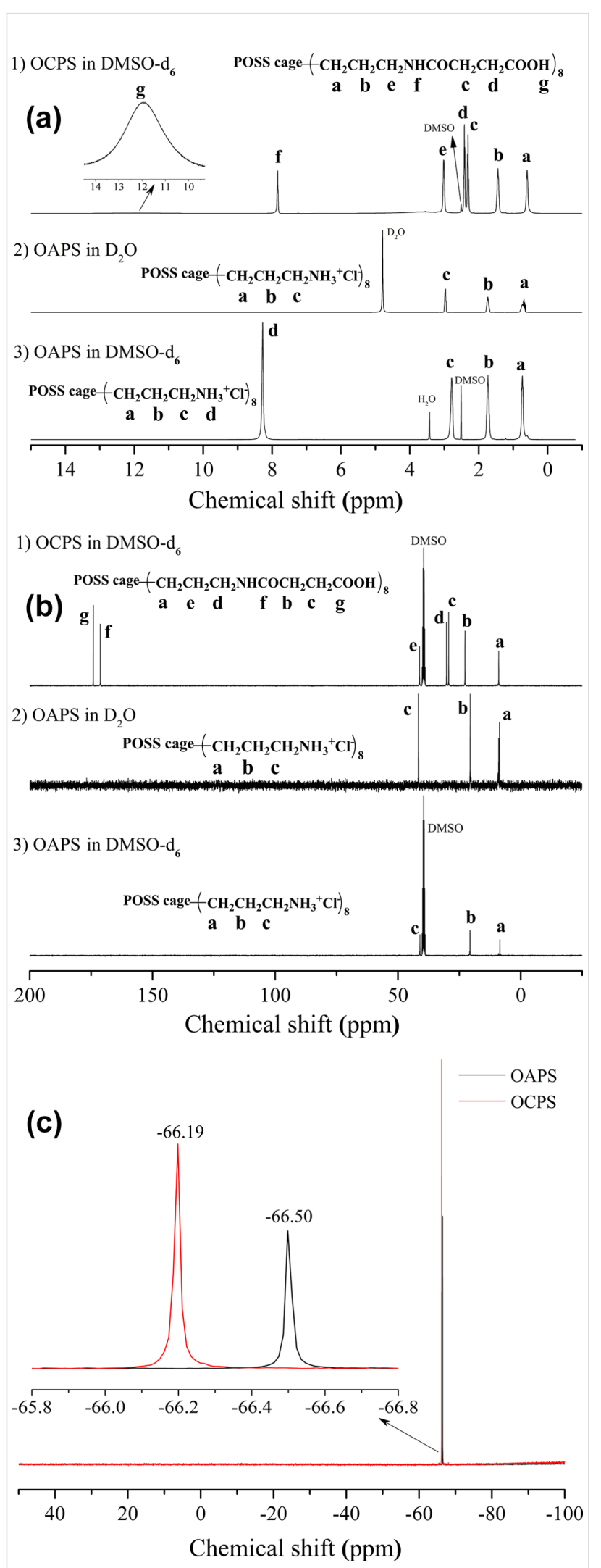

Figure 2: (a) ${ }^{1} \mathrm{H} N M R,(b){ }^{13} \mathrm{C}$ NMR and (c) ${ }^{29} \mathrm{Si} N M R$ spectra of OAPS and OCPS.
XRD: $2 \theta 7.23^{\circ}, 9.41^{\circ}, 9.75^{\circ}, 10.25^{\circ}, 10.43^{\circ}, 11.30^{\circ}, 20.61^{\circ}$, $21.30^{\circ}, 21.85^{\circ}, 22.33^{\circ}, 23.25^{\circ}$.

\section{Synthesis and structure characterization of OCPS-modified Mg-AI LDH}

The OCPS-modified Mg-Al LDH (denoted OLDH) was prepared via a one-step route [14] (Scheme 2). Unmodified pristine $\mathrm{NO}_{3}{ }^{-}-\mathrm{Mg}-\mathrm{Al} \mathrm{LDH}$ (denoted $\mathrm{NLDH}$ ) was prepared in the same way as a reference sample.

\section{FTIR and XPS}

FTIR is very useful in confirming the structures of LDH materials at the molecular level, as it provides important information about the interlayer anions. Figure 4 shows the FTIR spectra of NLDH and OLDH. The broad band in the range of $3700-3200 \mathrm{~cm}^{-1}$ is assigned to the $\mathrm{O}-\mathrm{H}$ stretching of the metal hydroxide layer and interlayer water molecules. Another band characteristic of the interlayer water is shown in the broad and weak peak around $1622 \mathrm{~cm}^{-1}$ in spectrum of NLDH, which is covered by the strong absorption bands of carboxylic ions and amide groups in the case of OLDH. As for NLDH, the strong absorption around $1381 \mathrm{~cm}^{-1}$ confirms the presence of interlayer $\mathrm{NO}_{3}{ }^{-}$, and the bands recorded below $800 \mathrm{~cm}^{-1}$ originate from the vibration of metal-oxygen bonds and from lattice vibrations associated with metal hydroxide sheets [15]. The introduction of OCPS anions after modification is confirmed by the new characteristic vibration bands detected for $-\mathrm{COO}^{-}$ $\left(\mathrm{C}=\mathrm{O}\right.$ asymmetric stretching at $1564 \mathrm{~cm}^{-1}$ and symmetric stretching at $\left.1409 \mathrm{~cm}^{-1}\right),-\mathrm{NH}-\mathrm{C}=\mathrm{O}(\mathrm{C}=\mathrm{O}$ stretching at $1638 \mathrm{~cm}^{-1}, \mathrm{C}-\mathrm{N}$ stretching and $\mathrm{N}-\mathrm{H}$ bending around 1310-1230 $\left.\mathrm{cm}^{-1}\right)$, alkyl (C-C-C asymmetric stretching at $1193 \mathrm{~cm}^{-1}, \mathrm{C}-\mathrm{H}$ stretching at $3000-2800 \mathrm{~cm}^{-1}$ ), and $\mathrm{Si}-\mathrm{O}-\mathrm{Si}$ (asymmetric stretching around $1000-1200 \mathrm{~cm}^{-1}$ ). The disappearance of the strong stretching vibration for carboxylic acid $\mathrm{C}=\mathrm{O}$ around $1701 \mathrm{~cm}^{-1}$ indicates that OCPS was almost totally converted into its ion state. Despite the possible fact that the band of residual nitrate might be mixed with the symmetric stretching of carboxylic ions around $1409 \mathrm{~cm}^{-1}$, the weakened absorption strength compared with that of NLDH suggests the nitrate was exchanged with OCPS carboxylic ions to a large extent. These results reveal the presence of OCPS anions in the OLDH structure and are consistent with the following XPS, XRD and elemental analysis results.

The presence of the elements $\mathrm{Mg}, \mathrm{Al}, \mathrm{Si}, \mathrm{O}, \mathrm{C}$ and $\mathrm{N}$ in $\mathrm{OLDH}$ is further confirmed by XPS. The survey spectra illustrated in Figure 5 show the peaks of electrons emitted from the $\mathrm{Mg} 2 \mathrm{p}$, $\mathrm{Mg} 2 \mathrm{~s}, \mathrm{Al} 2 \mathrm{p}$, and $\mathrm{Al} 2 \mathrm{~s}$ core levels. Compared to NLDH, these peaks in the brucite-like lattice show a small shift toward higher binding energies, probably arising from the interferences of OCPS intercalators. A similar phenomenon has been reported 

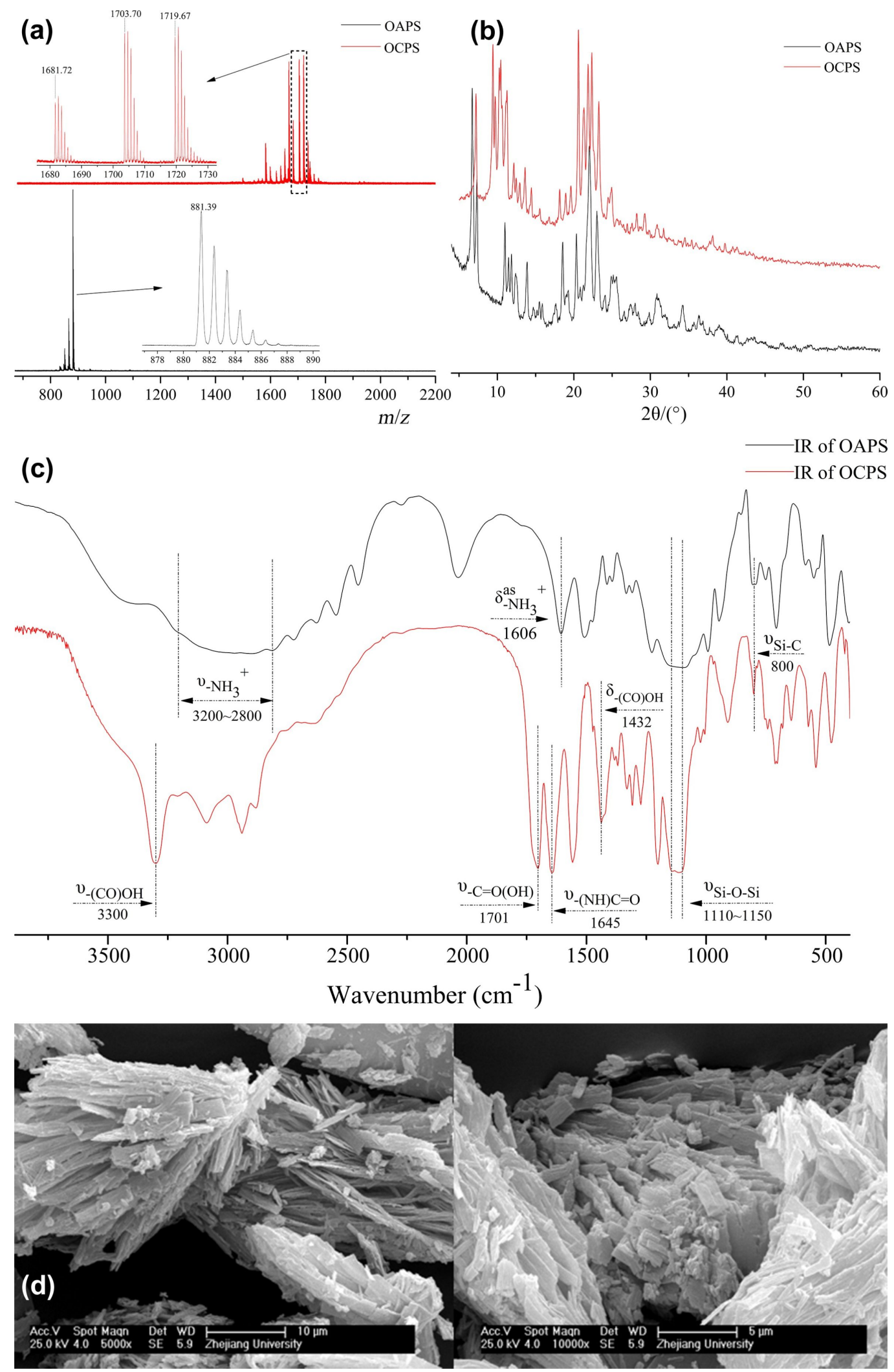

Figure 3: (a) MALDI-TOF-MS spectra, (b) XRD patterns and (c) FTIR spectra of OAPS and OCPS; (d) SEM images of OCPS. 

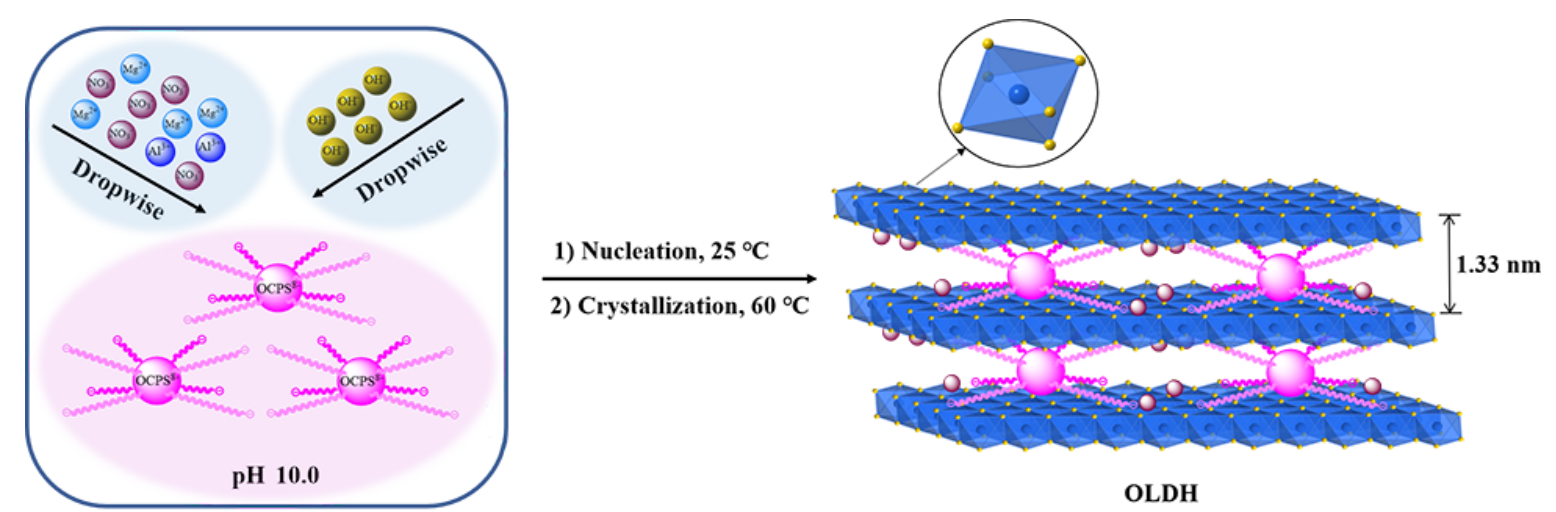

OLDH

Scheme 2: Schematic diagram of the synthesis of OLDH

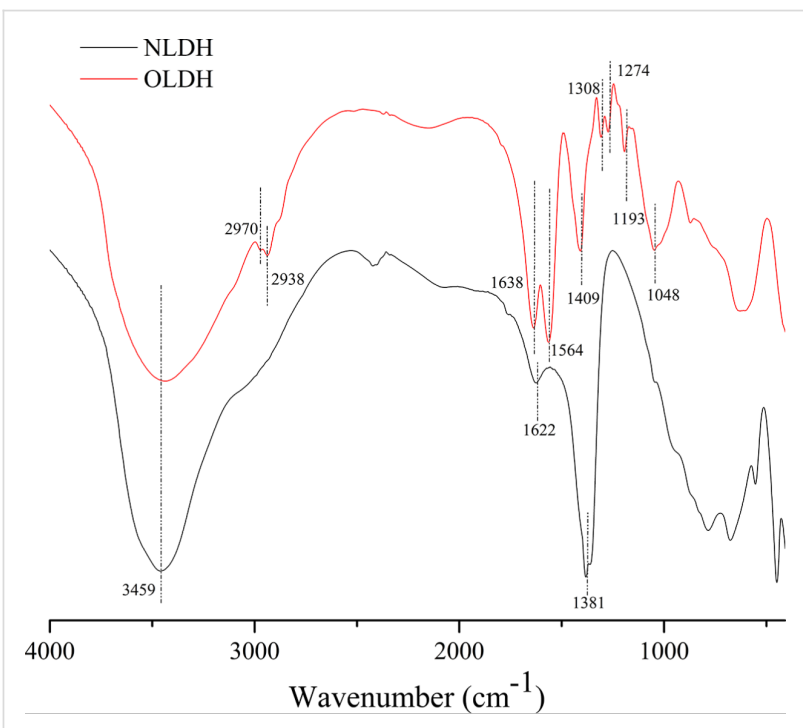

Figure 4: FTIR spectra of NLDH and OLDH.

before in the case of carbon black nanoparticles modified $\mathrm{Ni}-\mathrm{Fe}$ LDH [31].

\section{XRD}

The XRD patterns of NLDH and OLDH are presented in Figure 6a. These patterns exhibit a series of well-defined (00l) Bragg reflections with the basal spacing. In addition, higherorder reflections appear at low angles, and there are in-plane (110) peaks at high angles. The measurements indicate the formation of a layer-by-layer ordered stacking structure of $\mathrm{Mg}-\mathrm{Al}$ LDH crystallites. The first basal reflection (003) of NLDH at $2 \theta=9.83^{\circ}$ corresponds to an interlayer distance of $0.90 \mathrm{~nm}$. After the modification with OCPS, the position of the (003)

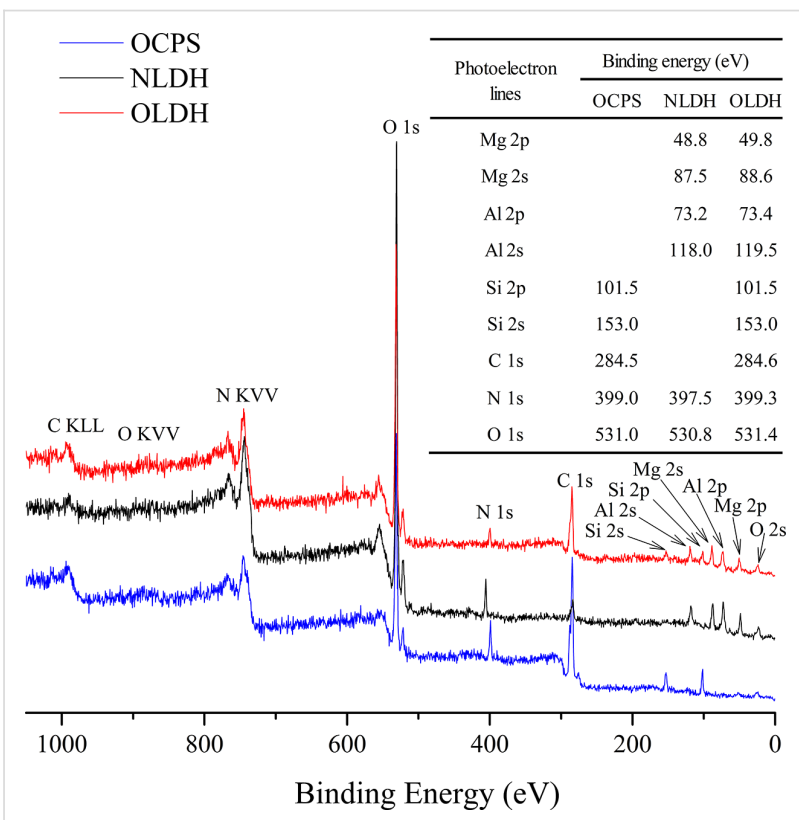

Figure 5: XPS spectra of OCPS, NLDH and OLDH.

reflection shifts to $6.62^{\circ}$, indicating an interlayer distance of $1.33 \mathrm{~nm}$ of OLDH. The enlargement of the interlayer spacing could be attributed to the relatively large intercalator molecules, and the decrease in peak pattern sharpness suggests a decline in crystallinity. The absence of any distinguishable reflection of OCPS or NLDH in the OLDH pattern indicates that unbonded excess OCPS was totally removed and no unmodified LDH phase is formed. This shows that OCPS anions can be efficiently intercalated within the LDH layers using the one-step method. The crystallite size and the average number of layers estimated from crystallite size and interlayer distance are 

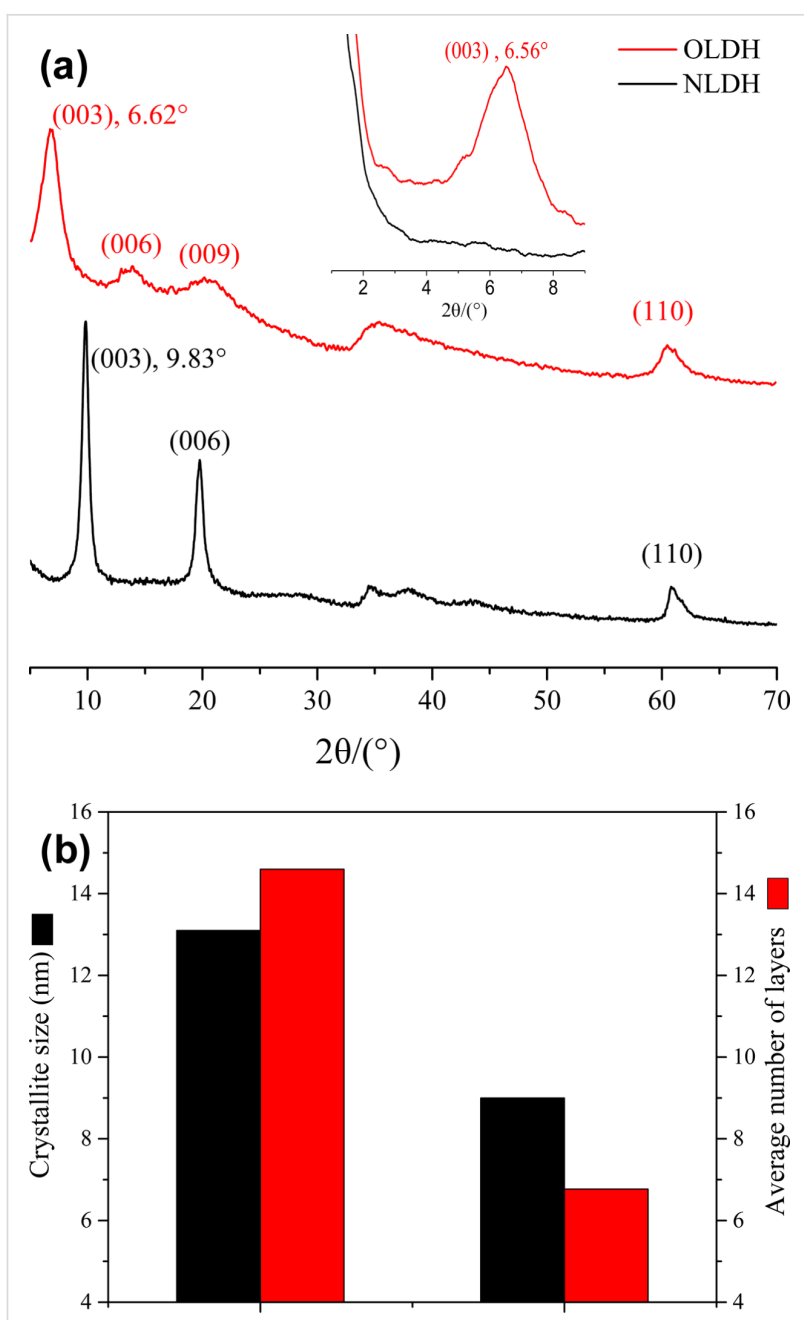

$\mathrm{NLDH}$

OLDH

Figure 6: (a) XRD patterns (WAXS: $\left.5-70^{\circ}, \mathrm{SAXS}: 1-10^{\circ}\right)$ and (b) crystallite size (thickness in the normal direction to the (00/) planes) of NLDH and OLDH.

plotted in Figure 6b. Compared to unmodified LDH, OLDH has a smaller crystallite size and shows a nearly two-fold reduction of the average number of layers. This drastic reduction could be explained as follows: With the interlayer spacing being increased by OCPS molecules, a large-size stacking of LDH laminae is sterically hindered [8].

Figure 7a schematically shows the possible brucite-like crystallographic structure of OLDH. The thickness of $\mathrm{Mg}-\mathrm{Al}$ hydroxide sheets is about $0.48 \mathrm{~nm}$ [32]. Here the intergallery spacing in the $\mathrm{Mg}-\mathrm{Al}$ hydroxide sheets for NLDH and OLDH were calculated as 0.42 and $0.85 \mathrm{~nm}$, respectively. It is a clear advantage of the one-step method that the possible presence of small organic anions in the interlayer region along with intercalator of much larger size hardly affects the interlayer distance [14]. The intergallery spacing of OLDH crystallites is mainly controlled by OCPS anions despite the possible existence of co-interca-
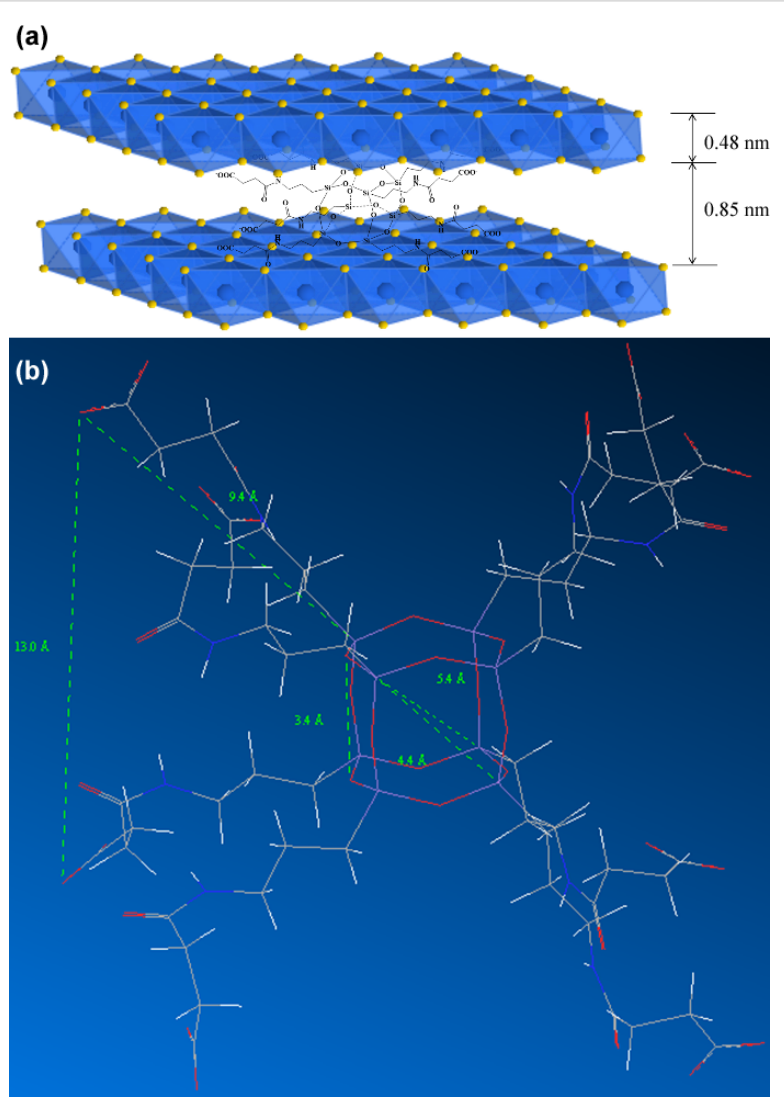

Figure 7: (a) Possible crystallographic structure of OLDH; (b) Energyminimized molecule structure of an OCPS anion (geometrically optimized by chem3D and HyperChem).

lating $\mathrm{NO}_{3}{ }^{-}$ions. Figure $7 \mathrm{~b}$ shows the energy-minimized molecule structure of the OCPS anion, with a dimension of the POSS core in the range of $0.34-0.54 \mathrm{~nm}$ and an approximate length of each POSS arm of $0.94 \mathrm{~nm}$. The side length of the whole cubiclike molecule is calculated as ca. $1.30 \mathrm{~nm}$, larger than the resulting intergallery spacing of OLDH, suggesting that OCPS anions in OLDH interlayers are probably in a restricted state. One possible explanation for this could be that the linear linkages present in the POSS structure are relatively flexible compared to the rigid silica cage, and that these long arms are rearranged under the action of forces arising during the synthetic process and from interlayer surroundings.

Furthermore, the interlayer features of OLDH are compared to those of traditional LDHs synthesized in a similar way, and the ratios between intergallery spacing and size of the intercalator molecules $(H / L)$ are summarized in Table 1. For LDHs intercalated with small inorganic molecules like $\mathrm{NO}_{3}{ }^{-}$and $\mathrm{CO}_{3}{ }^{2-}$, the ration $H / L$ reaches values as high as $3-4$, and the values are usually in the range of 1.1-1.8 in the case of LDHs modified with linear organic anions. In contrast, the LDH modified with OCPS seems to have a denser interlayer packing. Previous liter- 
ature suggests that the intercalation with linear organic molecules, e.g., surfactants, into pristine LDH can significantly weaken the hydrogen-bonding interactions between interlayer water, interlayer anions and the metal-hydroxide sheets. This largely reduces the contribution of the water layer accommodated in the interlayer region to the basal spacing $[15,19,33]$ Here, it is proposed that the less strongly bound interlayer water, which is further verified later by TGA results, might be another important factor accounting for the "compact structure" of OLDH.

\section{TEM and SEM}

The morphology of the LDHs was investigated through TEM and SEM, and the images are shown in Figure 8 and Figure 9, respectively. As can be observed from the contrast in Figure $8 \mathrm{a}-\mathrm{b}$, the primary particles of NLDH exhibit plate-like

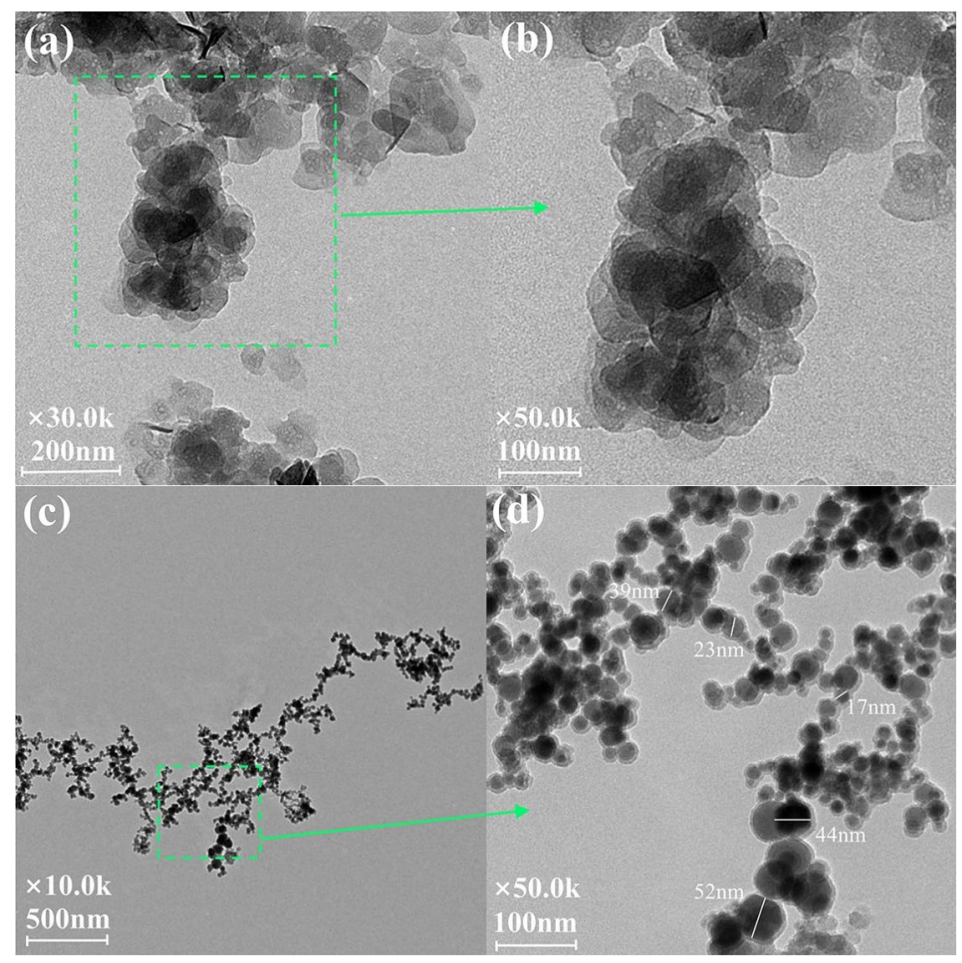

Figure 8: TEM images of $(a, b) N L D H$ and $(c, d)$ OLDH.
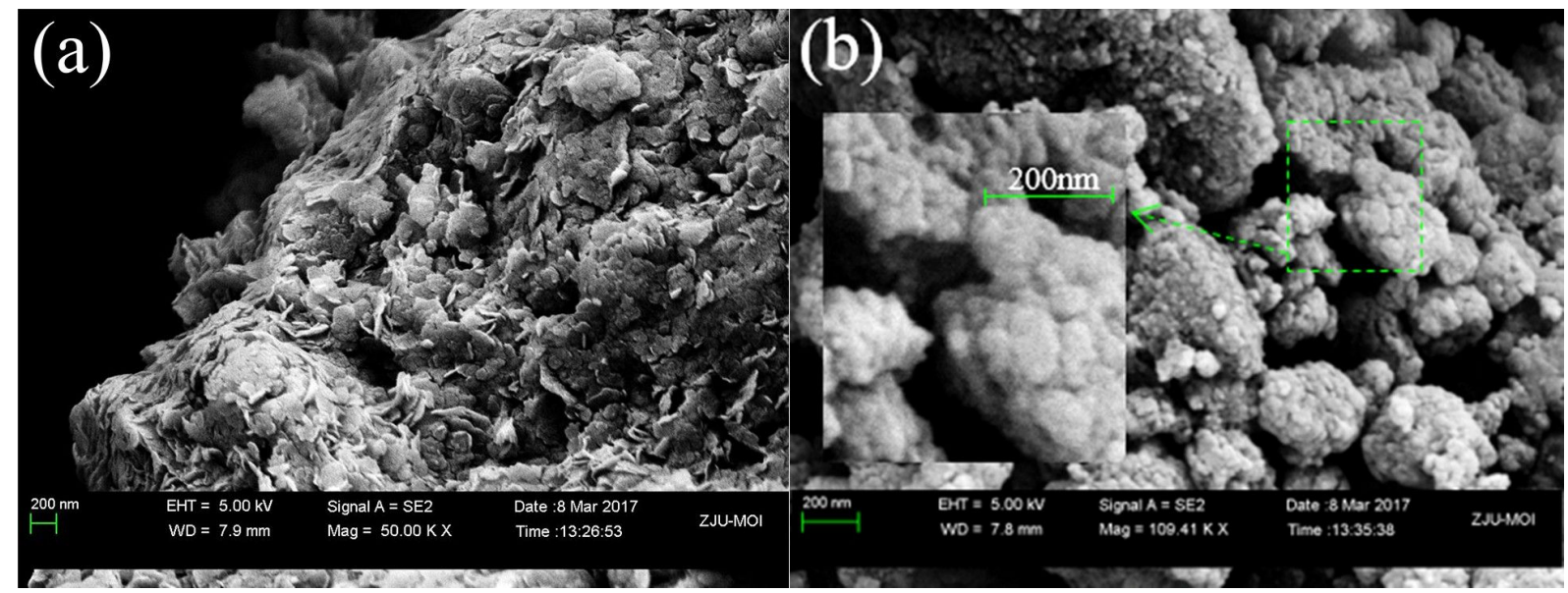

Figure 9: SEM images of (a) NLDH and (b) OLDH. 
Table 1: Ratio between intergallery spacing and intercalator molecule size $(H I L)$ of $L D H s$ synthesized via the one-step route with $\mathrm{Mg} / \mathrm{Al}(\mathrm{mol})=2[9,11,14]$.

\begin{tabular}{lll}
\multicolumn{2}{c}{ types of intercalators } & $H / L$ \\
\hline inorganic small molecules & $\mathrm{NO}_{3}{ }^{-}, \mathrm{CO}_{3}{ }^{2-}$ & $3-4$ \\
linear molecules & $\mathrm{SDBS}$ & 1.16 \\
& acid yellow 36 & 1.56 \\
& acid red 88 & 1.78 \\
& SIEPDPc & 1.22 \\
\hline
\end{tabular}

asodium 3-( $p$-anilinophenylazo)benzenesulfonate; bsodium 4(-2hydroxy-1-naphthylazo)naphthalenesulphonate; ${ }^{c}((1,1,3,3$-tetramethyldisiloxane-1,3-diyl)bis(propane-3,1-diyl))bis(2-methoxy-4,1phenylene)bis(phenylphosphonochloridate).

geometries with sizes mainly ranging from 100 to $200 \mathrm{~nm}$ in diameter and without any defined outer shape. The irregular and arc-like edges of most particles might be an indication of the incomplete process of crystal growth. On the other hand, the primary particles of OLDH in Figure $7 \mathrm{c}-\mathrm{d}$ are also found to be plate-like, with smaller sizes in the range of 10-50 nm in diameter. The intercalation of POSS anions does not significantly change the two-dimensional morphology of the LDH. The highly non-uniform sizes and imperfect edges of these particles are an implication for the incomplete growth of OLDH crystals, which might be ascribed to the huge steric hindrance of OCPS Through sufficient and suitable post-synthesis treatment, a welldefined geometry of all particles might be obtained.

The SEM micrographs in Figure 9 show that both LDHs have an agglomerated morphology. The plate-like geometry and the dimensions of NLDH are roughly in accordance with the results obtained from TEM. However, as the thickness of the platinum coating layer is about $15 \mathrm{~nm}$, close to the size of OLDH primary particles, the surface morphology of OLDH is not easily verified and seems to remind of stacked nuggets.

\section{Elemental analysis}

The OCPS-modified LDH can be represented by the chemical formula $\mathrm{Mg}_{2} \mathrm{Al}(\mathrm{OH})_{6} \mathrm{OCPS}_{x / 8}\left(\mathrm{NO}_{3}\right)_{1-x} \cdot 0.4 \mathrm{H}_{2} \mathrm{O}$, where OCPS is in its ionic state and $x$ is the degree of intercalation of OCPS. Based on elemental analysis data of carbon [C (wt \%)], $x$ can be calculated from the following equation:

$$
\mathrm{C}(\text { wt } \%)=\frac{7 x M_{\mathrm{C}}}{M_{\mathrm{OLDH}}}=\frac{84.1 x}{246.2+147.3 x},
$$

where $M_{\mathrm{C}}$ and $M_{\mathrm{OLDH}}$ are the molecular weights of carbon and $\mathrm{OLDH}$, respectively. A calculation based on the results in Table 2 shows that OLDH has an intercalation degree of $50.8 \%$, and the other anions remain $\mathrm{NO}_{3}{ }^{-}$as the co-intercalator with a molar ratio of $\mathrm{OCPS}^{8-} / \mathrm{NO}_{3}{ }^{-} \approx 1: 8$.
Table 2: Elemental analysis results of OLDH

$\begin{array}{ll}\mathrm{N}(\text { wt \%) } & 2.34 \\ \mathrm{C}(\text { wt \%) } & 13.30 \\ \mathrm{H}(\text { wt \%) } & 5.00\end{array}$

\section{Thermal stability and combustion behavior Thermal stability}

The thermal decomposition behavior was investigated to evaluate the thermal stability of LDHs, and the TGA thermograms are presented in Figure 10, with the measured data being summarized in Table 3. As can be seen in Figure 10a, the decomposition of NLDH under $\mathrm{N}_{2}$ atmosphere mainly undergoes three distinct steps, corresponding to the desorption process of interlayer water (up to about $240{ }^{\circ} \mathrm{C}$ ), the partial and complete loss of $\mathrm{OH}^{-}$from the hydroxide layer $\left(245-345^{\circ} \mathrm{C}\right.$ and $\left.345-420^{\circ} \mathrm{C}\right)$ and the denitration of interlayer nitrate ions $\left(420-580^{\circ} \mathrm{C}\right)$ $[3,4,34]$. The curve of OLDH is much different and demonstrates a single major stage of weight loss, which is largely due to the release of gaseous products from the decomposition of $\mathrm{OCPS}^{8-}$ accompanied by the dehydroxylation of the host mate-
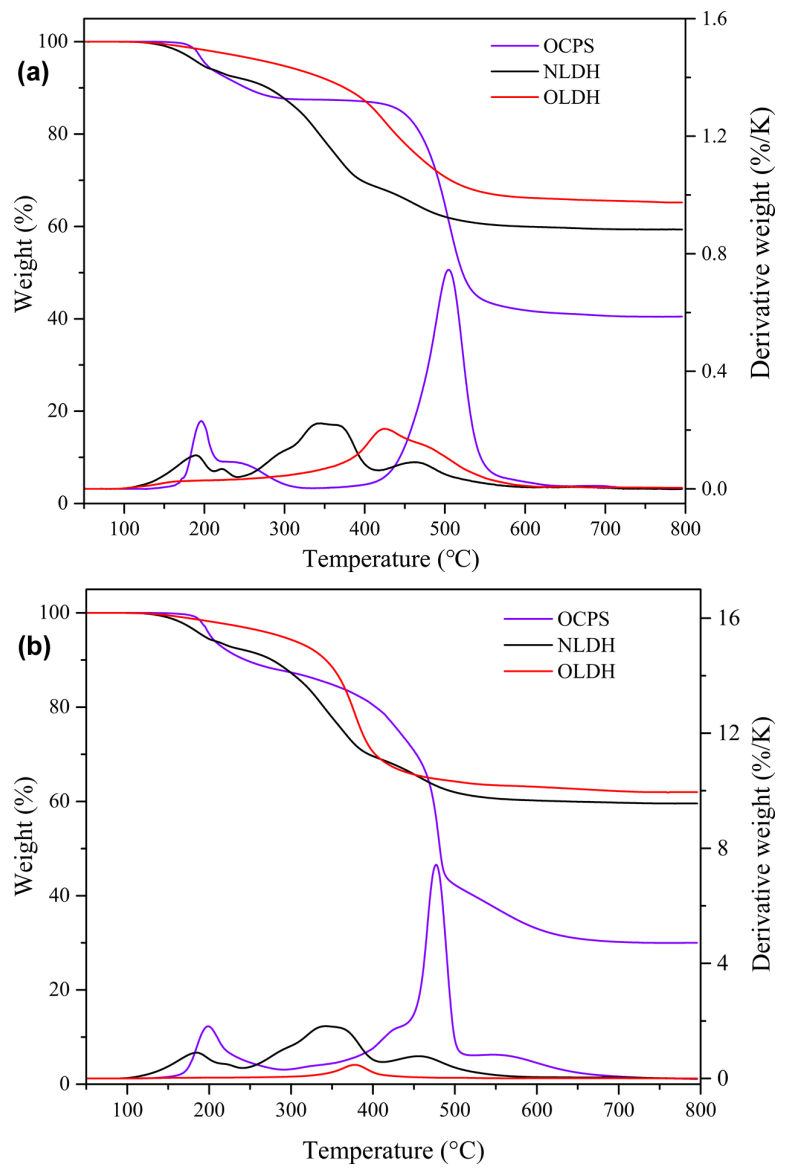

Figure 10: TG and DTG curves in (a) $\mathrm{N}_{2}$ and (b) air. 
Table 3: Comparison of TG and DTG data between OCPS, NLDH, OLDH and other organically modified Mg-Al LDHs in $\mathrm{N}_{2}$ and air.

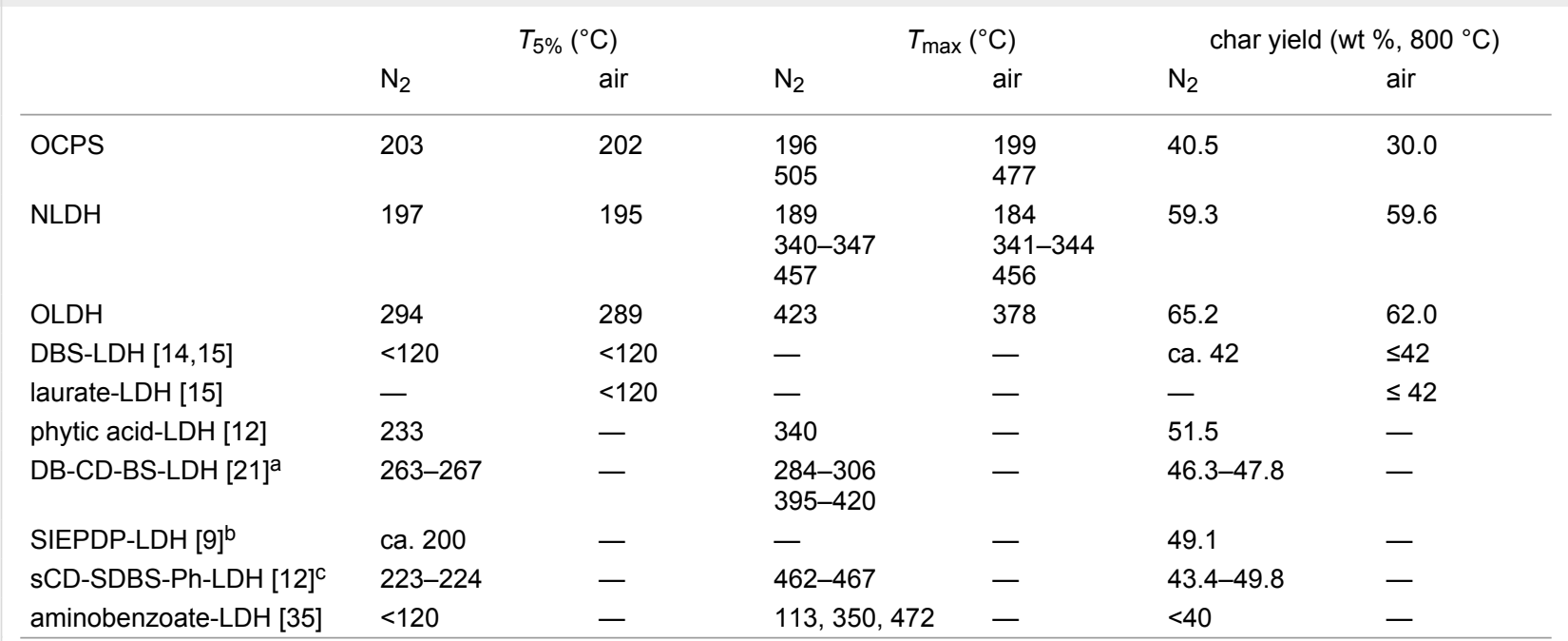

aLDH modified with a $\beta$-cyclodextrin derivative functionalized with a controllable carbon-carbon double bond; ${ }^{b} \mathrm{LDH}$ modified with a eugenol derivative containing silicon and phosphorus; ' ${ }^{2} \mathrm{DH}$ modified with hydroxypropyl-sulfobutyl- $\beta$-cyclodextrin (sCD), phytic acid (Ph) and sodium dodecylbenzene sulfonate (SDBS).

rial. OLDH exhibits a significantly higher initial decomposition temperature $\left(T_{5 \%}, 97{ }^{\circ} \mathrm{C}\right.$ higher $)$, an enhanced temperature at the maximum rate of degradation $\left(T_{\max }, 83{ }^{\circ} \mathrm{C}\right.$ higher) and an improved residue yield at $800{ }^{\circ} \mathrm{C}(10 \%$ higher $)$. Interestingly, as the initial decomposition temperature and char residue of OLDH are much higher than those of OCPS as well, some kind of synergistic effect might occur during the degradation process in the presence of POSS. Similar tendencies are also observed when the decomposition proceeds under air atmosphere (see Figure 10b) with the improvement being slightly decreased, owing to the more thorough decomposition of organic components. These observations clearly demonstrate that the thermal stability of OLDH is well-maintained and even enhanced in comparison to NLDH, and obviously surpasses most organically modified LDHs reported in the literature $[9,12,14,15,21,35]$, as can be seen from the comparison of TG data listed in Table 3.

To better understand the thermal degradation behavior, the kinetics of LDH degradation in a nitrogen atmosphere was studied using the Ozawa-Flynn-Wall (OFW) method [36,37]. The conversion ( $\alpha$, defined as the ratio of actual weight loss to total weight loss) as a function of the temperature at various heating rates $(\beta)$ is shown in Figure $11 \mathrm{a}-\mathrm{b}$ and the plots of $\log (\beta)$ versus $1 / T$ for different values of $\alpha$ are presented in Figure $11 \mathrm{c}-\mathrm{d}$ with decent linearity for both LDHs, indicating the applicability of the OFW method to our system in the investigated conversion range. The apparent activation energies $(E \alpha)$ are calculated from the slopes of these lines using the following expression:

$$
E_{\alpha}=- \text { slope } \cdot \frac{R}{0.457}
$$

The fitting results and E $\alpha$ data are summarized in Table 4. Results show that the apparent activation energy increases as a whole with increasing conversion. Combined with the TGA data and the data of $\alpha$ as a function of $T$, the $E_{\alpha}$ values of NLDH can be roughly divided into four distinct intervals, namely $80-90 \mathrm{~kJ} \cdot \mathrm{mol}^{-1}$ (desorption of interlayer water at $\alpha<0.12$ ), $113-114 \mathrm{~kJ} \cdot \mathrm{mol}^{-1}$ (primary dehydroxylation of the hydroxide layer at $\alpha=0.22-0.50), 114-140 \mathrm{~kJ} \cdot \mathrm{mol}^{-1}$ (complete dehydroxylation at $\alpha=0.50-0.80$ ), $140-160 \mathrm{~kJ} \cdot \mathrm{mol}^{-1}$ (denitration at $\alpha>0.85$ ). On the other hand, the $E_{\alpha}$ values of OLDH increase continuously as $\alpha$ increases from 0.05 to 0.80 and remain in the range of $185-190 \mathrm{~kJ} \cdot \mathrm{mol}^{-1}$. It is obvious that the incorporation of the POSS structure into LDH can improve the activation energies over a wide range of reaction extents $(\alpha=0.1-0.95)$, leading to the enhancement of thermal stability.

Furthermore, the morphology of char residues after thermal degradation in both $\mathrm{N}_{2}$ and air was investigated through SEM with the images shown in Figure 12, and the change of surface components before and after degradation were examined through XPS with plots presented in Figure 13. The char of the intercalator OCPS exhibits a shrinkage with a very smooth and continuous dense surface in both $\mathrm{N}_{2}$ and air, due to the remarkable surface enrichment effect of silica during heating, which can be proved in the XPS spectra shown in Figure 13a. In the case of NLDH, the structure of LDH layers was completely destroyed by dehydroxylation, resulting in the formation of 

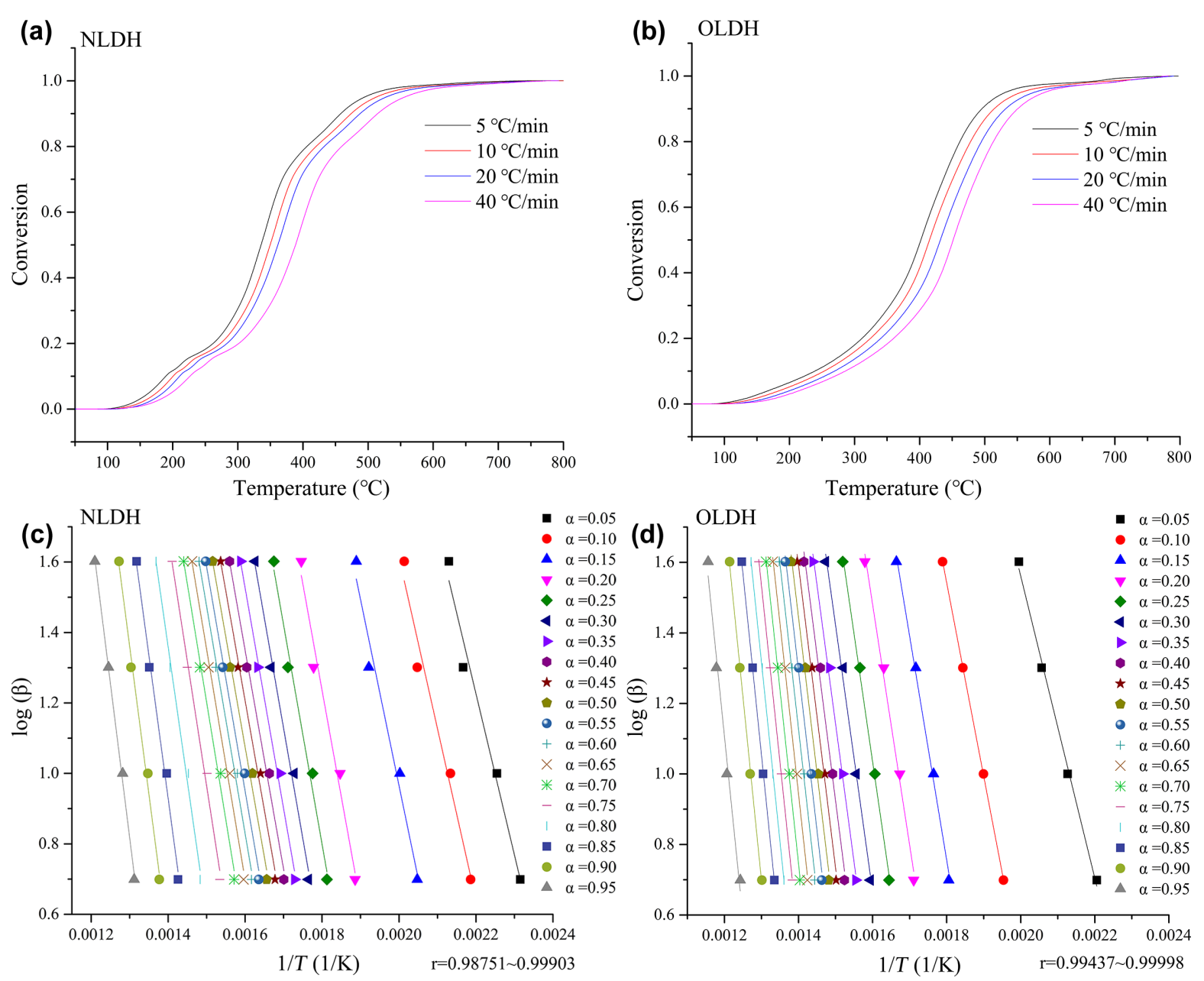

Figure 11: $(a, b)$ Typical conversion curves at different heating rates and $(c, d)$ plots of $\log (\beta)$ as a function of $1 / T$ at different values of $\alpha$.

random stacking of mixed oxides containing $\mathrm{Mg}$ and $\mathrm{Al}$ [34]. The surface after degradation in air seems not as rough and coarse as that after degradation in $\mathrm{N}_{2}$, which might be caused by the different gas release process at high temperatures. The situation regarding OLDH is found to be very unique. The surfaces are much smoother and more compact compared to NLDH, demonstrating the char features of silicone materials. In more detail, the char of OLDH after degradation in $\mathrm{N}_{2}$ is composed of distinct laminas stacked together compactly and the char after degradation in air consists of dense blocks. It is proposed here that the flexible nature of polysiloxane and its weak intermolecular forces give rise to low surface energy and a high spreading coefficient. When heated, the siloxane moiety migrates to the surface and reacts with the metal oxides to form a continuous and compact condensed phase. This mixed carbonized protecting layer provides a good barrier to the transfer of heat and mass, preventing the inner layer against further decomposition and accelerating the formation of char. Evidence in favor of this assumption can be observed from the XPS results presented in Figure 13c. In addition, the significantly increased carbon content after degradation in air compared to that of OCPS also implies a synergistic effect of $\mathrm{Mg}-\mathrm{Al}$ oxide and siloxane.

\section{Combustion behavior}

The flammability of OLDH was assessed measuring the heat-release properties by using microscale combustion calorimetry (MCC). Heat-release rate (HRR), peak heat-release rate (pHRR), the heat-release capacity (HRC) and total heat release (THR) were measured. The combustion results were compared with that of the commonly used LDH modified with sodium dodecyl benzenesulfonate (SDBS, denoted as DBS-LDH). The HRR curves are plotted in Figure 14, and the corresponding combustion data are listed in Table 5. Typically, in the HRR curve of DBS-LDH, two stages of the combustion process can be distinguished by two separate peaks, which correspond to the combustion of a small amount of unbounded residual SDBS at lower temperature (around $186^{\circ} \mathrm{C}$ ) and the thermal decomposition of intercalated SDBS segments at higher temperature 


\begin{tabular}{|c|c|c|}
\hline \multirow[t]{2}{*}{$\alpha$} & \multicolumn{2}{|c|}{$E_{\alpha} / \mathrm{kJ} \cdot \mathrm{mol}^{-1}$} \\
\hline & $\mathrm{NLDH}$ & OLDH \\
\hline 0.05 & 83.26 & 77.90 \\
\hline 0.10 & 88.43 & 99.85 \\
\hline 0.15 & 96.09 & 115.49 \\
\hline 0.20 & 109.92 & 124.20 \\
\hline 0.25 & 113.22 & 131.66 \\
\hline 0.30 & 113.93 & 137.34 \\
\hline 0.35 & 113.95 & 142.90 \\
\hline 0.40 & 113.05 & 150.17 \\
\hline 0.45 & 112.91 & 156.04 \\
\hline 0.50 & 113.48 & 160.72 \\
\hline 0.55 & 115.76 & 165.22 \\
\hline 0.60 & 117.29 & 170.22 \\
\hline 0.65 & 119.00 & 175.68 \\
\hline 0.70 & 121.73 & 179.16 \\
\hline 0.75 & 128.55 & 182.27 \\
\hline 0.80 & 139.18 & 185.26 \\
\hline 0.85 & 147.59 & 187.04 \\
\hline 0.90 & 152.47 & 189.39 \\
\hline 0.95 & 159.13 & 187.46 \\
\hline
\end{tabular}

(around $467^{\circ} \mathrm{C}$ ). The excess SDBS is believed hard to be completely removed by simple purification procedures such as washing with water or centrifugation during LDH preparation [21]. In contrast, the HRR curve of OLDH displays a single peak around $458{ }^{\circ} \mathrm{C}$, corresponding to the thermal decomposition of OCPS anions in LDH interlayers. The absence of a peak at lower temperatures suggests the purity of OLDH, which was consistent with the preceding IR and XRD results and also revealed the ease of purification of OLDH. Additionally, the temperature at the maximal pyrolysis rate $\left(T_{\max }\right)$ showed no significant difference between these two LDHs. The pHRR and HRC values for OLDH were only $31.5 \%$ and $36.1 \%$, respectively, of those for DBS-LDH, and the THR value was reduced by half. These results indicate that the potential hazards posed from a fire for OCPS-modified LDH are markedly decreased compared to SDBS-modified LDH.

\section{Conclusion}

In summary, a novel LDH modified with an octa-substituted carboxy-terminated POSS (OLDH) was designed and prepared via a one-step route. The structure and micromorphology of OLDH were confirmed by FTIR, XPS, XRD, TEM, SEM and elemental analysis. Results showed that OLDH exhibited an increased interlayer distance of $1.33 \mathrm{~nm}$, a nearly two-fold reduction in the average number of layers compared to unmodified $\mathrm{NO}_{3}{ }^{-}$-LDH (NLDH), plate-like primary particles with diameters ranging from 10 to $50 \mathrm{~nm}$, and an intercalation degree of about $50.8 \%$. TGA investigation demonstrated the thermal stability of OLDH was effectively enhanced after the incorporation of the POSS structure, and the thermal degradation kinetics in $\mathrm{N}_{2}$ revealed that the apparent activation energies were impressively raised over a wide range of reaction extents ( $\alpha=0.1-0.95$ ). Besides, a synergistic effect between the siloxane moiety and the $\mathrm{Mg}-\mathrm{Al}$ hydroxide was found during thermal degradation, facilitating the char formation. Finally, the MCC results showed the combustion performance of OLDH far surpassed that of the commonly used SDBS-modified LDH.

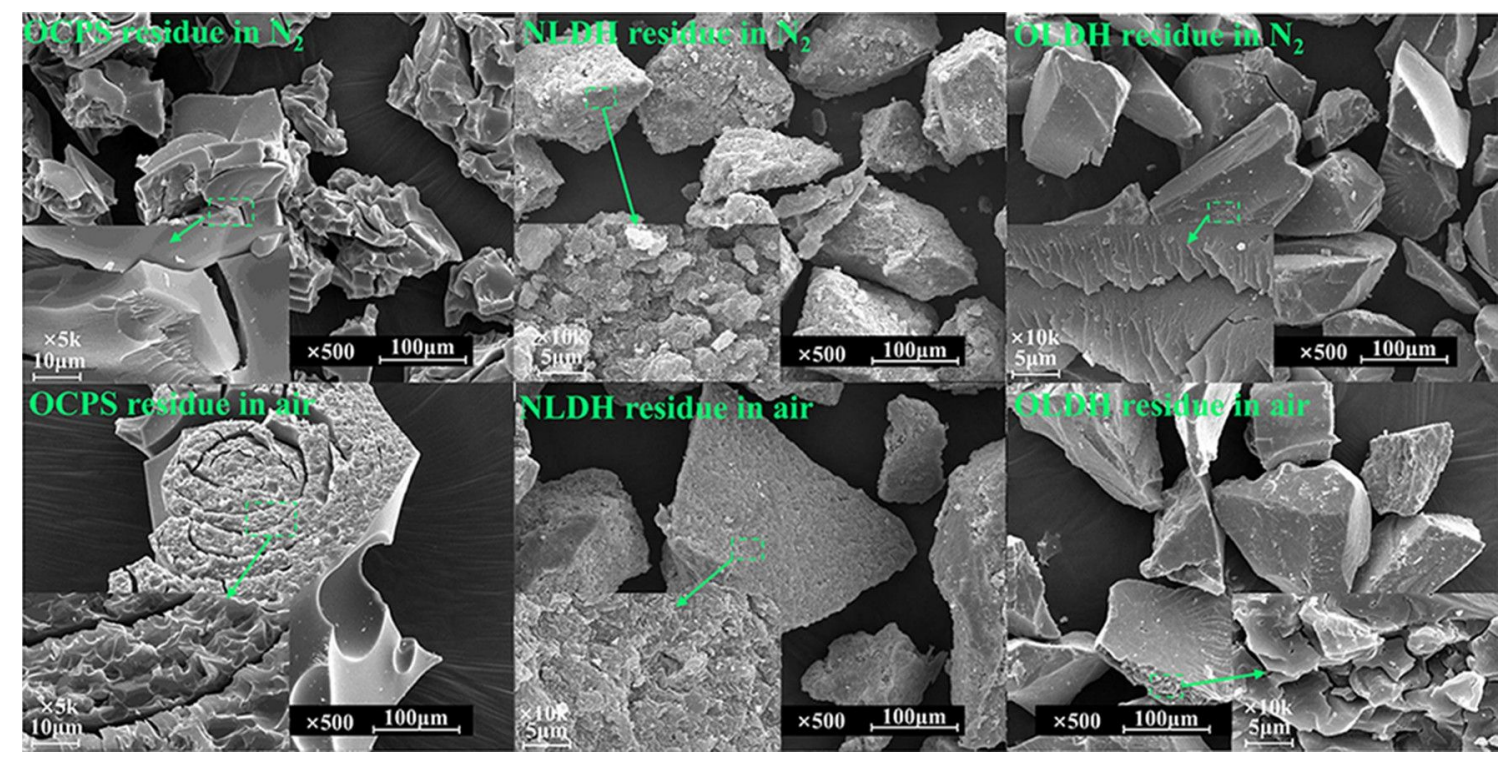

Figure 12: SEM morphology of char residues at $800^{\circ} \mathrm{C}$. 


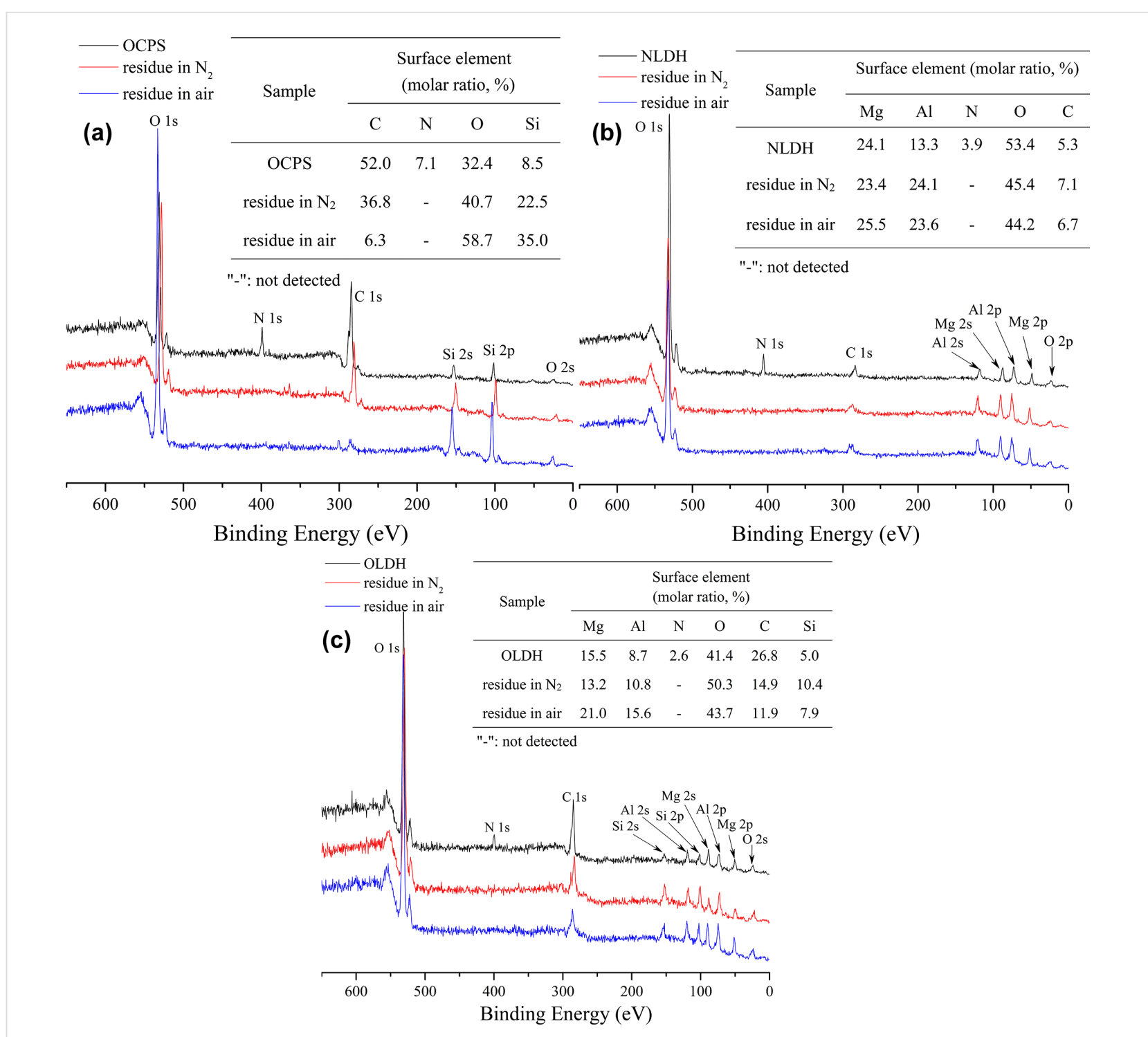

Figure 13: XPS measurements of surface components before and after thermal degradation of (a) OCPS, (b) NLDH and (c) OLDH).

This research offers a new approach to preparing modified LDHs with enhanced thermal stability and low flammability, and the POSS-modified LDH is expected to represent a powerful candidate for applications in LDH-based materials.

\section{Experimental \\ Materials}

All chemicals were of analytical grade and used as received without further purification unless otherwise noted. (3-Aminopropyl)triethoxysilane and succinic anhydride were purchased from Aladdin Co. Ltd (Shanghai, China). Methanol, chloroform, formic acid, magnesium(II) nitrate hexahydrate $\left(\mathrm{Mg}\left(\mathrm{NO}_{3}\right)_{2} \cdot 6 \mathrm{H}_{2} \mathrm{O}\right)$, aluminum(III) nitrate nonahydrate $\left(\mathrm{Al}\left(\mathrm{NO}_{3}\right)_{3} \cdot 9 \mathrm{H}_{2} \mathrm{O}\right)$, sodium hydroxide $(\mathrm{NaOH})$, tetrahydrofuran (THF) and concentrated hydrochloric acid (36.0-38.0 wt \%) were obtained from Sinopharm Chemical Reagent Co., Ltd (Shanghai, China). Ultrapure water with a resistance of $18.25 \mathrm{M} \Omega \cdot \mathrm{cm}$ was used for all experiments.

\section{Synthesis of octa-ammonium POSS and octa-substituted carboxy-terminated POSS}

Octa-ammonium POSS (OAPS) was prepared using a modified refluxing method [28-30]. Typically, to a $1 \mathrm{~L}$ flask equipped with a condenser and a magnetic stirrer, (3-aminopropyl)triethoxysilane $(30 \mathrm{~mL})$, methanol $(720 \mathrm{~mL})$ and concentrated hydrochloric acid $(60 \mathrm{~mL})$ were added. The system was refluxed for $20 \mathrm{~h}$ under vigorous stirring and then cooled down to room temperature. The white precipitate was collected after precipitation in cold THF, filtration, and washing with cold methanol. The residue was then recrystallized in methanol, 


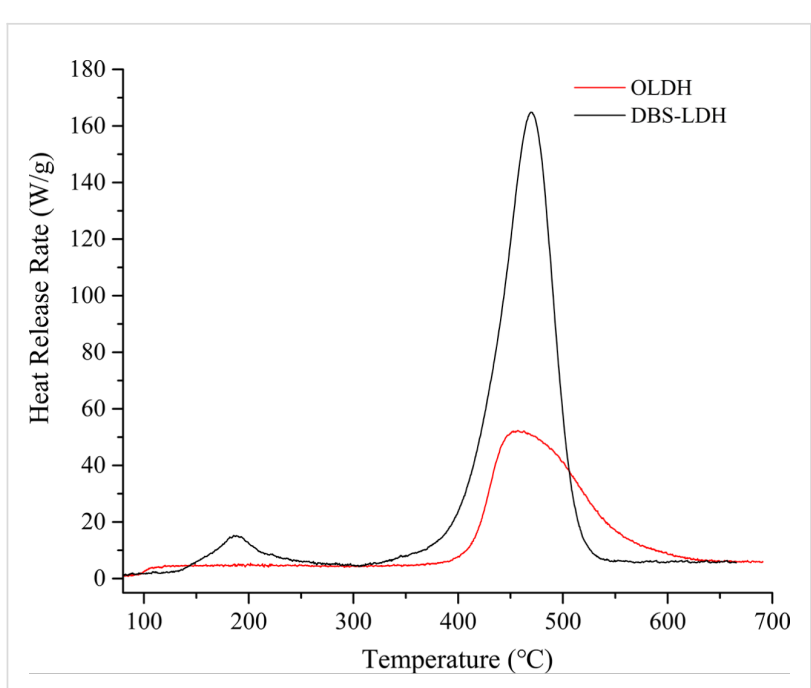

Figure 14: HRR curves of DBS-LDH adapted from [21] and OLDH.

\begin{tabular}{|c|c|c|}
\hline & DBS-LDH & OLDH \\
\hline $\mathrm{pHRR}\left(\mathrm{W} \cdot \mathrm{g}^{-1}\right)$ & 165.0 & 52.0 \\
\hline $\operatorname{HRC}\left(\mathrm{J} \cdot \mathrm{g}^{-1} \cdot \mathrm{K}^{-1}\right)$ & 158.0 & 57.0 \\
\hline $\operatorname{THR}\left(\mathrm{kJ} \cdot \mathrm{g}^{-1}\right)$ & 10.0 & 4.8 \\
\hline$T_{\max }\left({ }^{\circ} \mathrm{C}\right)$ & 467 & 458 \\
\hline
\end{tabular}

filtrated, and dried in vacuum $\left(40{ }^{\circ} \mathrm{C}, 24 \mathrm{~h}\right)$. The final product was obtained as a white powder with a yield of $43 \%$.

The synthesis of octa-substituted carboxy-terminated POSS (OCPS) was carried out via acylation of OAPS with succinic acid [38]. In detail, to a solution of OAPS (15 g) and triethylamine $(15 \mathrm{~mL})$ in methanol $(750 \mathrm{~mL})$, succinic anhydride $(60 \mathrm{~g})$ was added, and the reaction mixture was stirred vigorously for $2 \mathrm{~h}$ at room temperature. White solid was afforded after precipitation in cold chloroform, filtration and washing with chloroform and THF. The crude product was further purified by being resolved in formic acid and reprecipitated in water, filtrated and washed with water until the $\mathrm{pH}$ value of the filtrate was 7 . The solid was then dried in vacuum $\left(40{ }^{\circ} \mathrm{C}, 24 \mathrm{~h}\right)$, to give a white powder with a yield of $69 \%$.

\section{Synthesis of OCPS-intercalated Mg-AI LDH}

The OCPS-intercalated $\mathrm{Mg}_{2} \mathrm{Al}_{1} \mathrm{LDH}$ (denoted OLDH) was prepared via a one-step route [14]. Typically, in a $1 \mathrm{~L}$ flask equipped with a condenser, a $\mathrm{pH}$ meter, a nitrogen inlet tube and a magnetic stirrer, OCPS $(8.40 \mathrm{~g}, 5.0 \mathrm{mmol})$ and water $(200 \mathrm{~mL})$ were placed under nitrogen. The mixture was stirred vigorously at room temperature and the $\mathrm{pH}$ value was adjusted to 10 by adding $1 \mathrm{M} \mathrm{NaOH}$ solution. After the system became clear and transparent, an aqueous solution containing $\mathrm{Mg}\left(\mathrm{NO}_{3}\right)_{2} \cdot 6 \mathrm{H}_{2} \mathrm{O}(10.256 \mathrm{~g}, 40 \mathrm{mmol})$ and $\mathrm{Al}\left(\mathrm{NO}_{3}\right)_{3} \cdot 9 \mathrm{H}_{2} \mathrm{O}$ (7.503 g, $20 \mathrm{mmol})$ in water $(200 \mathrm{~mL})$ was slowly added via micro syringe pump. During the synthesis, the $\mathrm{pH}$ value was maintained at $10 \pm 0.02$ by adding a suitable amount of $\mathrm{NaOH}$ solution. The resulting slurry was continuously stirred for $30 \mathrm{~min}$ and then allowed to age at $60^{\circ} \mathrm{C}$ for more than $18 \mathrm{~h}$. The precipitate was filtered and washed once with $\mathrm{NaOH}$ solution of $\mathrm{pH} 10$, followed by thoroughly washing with water until the $\mathrm{pH}$ value of the filtrate was 7 . The final product OLDH was obtained after drying at $80{ }^{\circ} \mathrm{C}$ in a blast drier for $4 \mathrm{~h}$ followed by $80^{\circ} \mathrm{C}$ in vacuum for $24 \mathrm{~h}$. In addition, unmodified pure $\mathrm{LDH}$ $\left(\mathrm{NO}_{3}{ }^{-}-\mathrm{Mg}-\mathrm{Al} \mathrm{LDH}\right.$, denoted $\left.\mathrm{NLDH}\right)$ and sodium dodecylbenzenesulfonate-modified LDH (denoted DBS-LDH) were synthesized via the same method.

\section{Characterization}

${ }^{1} \mathrm{H}$ NMR and ${ }^{13} \mathrm{C}$ NMR spectra were recorded in DMSO- $d_{6}$ or $\mathrm{D}_{2} \mathrm{O}$ with a Bruker Avance III 400 spectrometer, and ${ }^{29} \mathrm{Si}$ NMR spectra were recorded in DMSO- $d_{6}$ with a Bruker DMX 500 spectrometer. FTIR spectra were measured with a Nicolet 560 spectrometer, using $\mathrm{KBr}$ pellets. X-ray diffraction was measured using an X'Pert PRO diffractometer with $\mathrm{Cu} \mathrm{K} \alpha$ radiation $(\lambda=0.154 \mathrm{~nm})$. Wide-angle X-ray scattering (WAXS) was measured in the range of $2 \theta=3-70^{\circ}$ with a step width of $0.026^{\circ}$, and small-angle X-ray scattering (SAXS) was measured in the range of $2 \theta=1-10^{\circ}$ with a step width of $0.013^{\circ}$. The LDH interlayer distance was calculated using Bragg's law. Elemental analysis was performed using an Elementar Vario MICRO cube. Samples were analyzed in triplicate with a mass of $2 \mathrm{mg}$ for each measurement. Matrix-assisted laser desorption/ ionization-time of flight (MALDI-TOF) mass spectra were recorded with a Bruker Daltonics UltrafleXtreme using methanol as solvent and 2,5-dihydroxybenzoic acid as matrix. X-ray photoelectron spectroscopy (XPS) was carried out on a VG ESCALABMK II electron energy spectrometer using $\mathrm{Mg} \mathrm{K} \alpha$ $(1253.6 \mathrm{eV})$ as the X-ray excitation source. Transmission electron microscopy (TEM) images were recorded on an HT-7700 microscope with an acceleration voltage of $100.0 \mathrm{kV}$ and bright-field illumination. The samples were dispersed in methanol/water mixed solvent, dropped onto carbon-coated copper grid and dried in a fume hood before characterization. Scanning electron microscopy (SEM) images were recorded on an SU-70 or Utral 55 to study the surface morphologies. The samples were placed on a conducting carbon cement holder and were then coated with a thin layer of platinum using a sputter coater. Thermogravimetric analysis (TGA) was performed on a TA-Q500 thermogravimeter at a heating rate of $10 \mathrm{~K} \cdot \mathrm{min}^{-1}$ from room temperature to $800{ }^{\circ} \mathrm{C}$ under a nitrogen flow of $100 \mathrm{~mL} \cdot \mathrm{min}^{-1}$ or air atmosphere of $60 \mathrm{~mL} \cdot \mathrm{min}^{-1} \mathrm{O}_{2}$ stream and $40 \mathrm{~mL} \cdot \mathrm{min}^{-1} \mathrm{~N}_{2}$ stream. Each sample was measured 
in an alumina crucible in triplicate, with a copy mass about $15 \mathrm{mg}$. The combustion behavior of the LDHs was measured using an FTT MCC-1 microscale combustion calorimeter, at a heating rate of $1 \mathrm{~K} \cdot \mathrm{s}^{-1}$ from 50 to $700{ }^{\circ} \mathrm{C}$ under a nitrogen flow of $100 \mathrm{~cm}^{3} \cdot \mathrm{min}^{-1}$. The volatile, anaerobic thermal degradation products were mixed with a $20 \mathrm{~cm}^{3} \cdot \mathrm{min}^{-1}$ gas stream containing $20 \% \mathrm{O}_{2}$ and $80 \% \mathrm{~N}_{2}$ prior to being added to a $900{ }^{\circ} \mathrm{C}$ combustion furnace. Each sample was measured in triplicate with a copy mass of about $5 \mathrm{mg}$, and the results were averaged.

\section{Acknowledgements}

C. Bittencourt is Research Associate of the National Funds for Scientific Research (FRS-FNRS, Belgium). The financial support from National Natural Science Foundation of China (NSFC, No.21636008) is gratefully acknowledged.

\section{ORCID ${ }^{\circledR}$ iDs}

Xianwei Zhang - https://orcid.org/0000-0001-8996-1323 Zhongzhu Ma - https://orcid.org/0000-0002-7088-3035 Hong Fan - https://orcid.org/0000-0002-9150-8912 Carla Bittencourt - https://orcid.org/0000-0002-3330-6693 Jintao Wan - https://orcid.org/0000-0002-6877-5625 Philippe Dubois - https://orcid.org/0000-0003-1534-1564

\section{References}

1. Taylor, H. F. W. Mineral. Mag. 1973, 39, 377-389. doi:10.1180/minmag.1973.039.304.01

2. Reichle, W. T. Solid State Ionics 1986, 22, 135-141. doi:10.1016/0167-2738(86)90067-6

3. Cavani, F.; Trifirò, F.; Vaccari, A. Catal. Today 1991, 11, 173-301. doi:10.1016/0920-5861(91)80068-k

4. Zhao, Y.; Li, F.; Zhang, R.; Evans, D. G.; Duan, X. Chem. Mater. 2002, 14, 4286-4291. doi:10.1021/cm020370h

5. Chen, W.; Qu, B. Chem. Mater. 2003, 15, 3208-3213. doi:10.1021/cm030044h

6. Manzi-Nshuti, C.; Songtipya, P.; Manias, E.; Jimenez-Gasco, M. M.; Hossenlopp, J. M.; Wilkie, C. A. Polymer 2009, 50, 3564-3574. doi:10.1016/j.polymer.2009.06.014

7. Costa, F. R.; Abdel-Goad, M.; Wagenknecht, U.; Heinrich, G. Polymer 2005, 46, 4447-4453. doi:10.1016/j.polymer.2005.02.027

8. Purohit, P. J.; Huacuja-Sánchez, J. E.; Wang, D.-Y.; Emmerling, F.; Thünemann, A.; Heinrich, G.; Schönhals, A. Macromolecules 2011, 44, 4342-4354. doi:10.1021/ma200323k

9. Li, C.; Wan, J.; Kalali, E. N.; Fan, H.; Wang, D.-Y. J. Mater. Chem. A 2015, 3, 3471-3479. doi:10.1039/c4ta05740f

10. Kalali, E. N.; Wang, X.; Wang, D.-Y. J. Mater. Chem. A 2015, 3, 6819-6826. doi:10.1039/c5ta00010f

11. Kang, N.-J.; Wang, D.-Y.; Kutlu, B.; Zhao, P.-C.; Leuteritz, A.; Wagenknecht, U.; Heinrich, G. ACS Appl. Mater. Interfaces 2013, 5, 8991-8997. doi:10.1021/am4020555

12. Kalali, E. N.; Wang, X.; Wang, D.-Y. J. Mater. Chem. A 2016, 4, 2147-2157. doi:10.1039/c5ta09482h

13. Li, C.; Wan, J.; Pan, Y.-T.; Zhao, P.-C.; Fan, H.; Wang, D.-Y. ACS Sustainable Chem. Eng. 2016, 4, 3113-3121. doi:10.1021/acssuschemeng.6b00134
14. Wang, D.-Y.; Costa, F. R.; Vyalikh, A.; Leuteritz, A.; Scheler, U.; Jehnichen, D.; Wagenknecht, U.; Häussler, L.; Heinrich, G. Chem. Mater. 2009, 21, 4490-4497. doi:10.1021/cm901238a

15. Costa, F. R.; Leuteritz, A.; Wagenknecht, U.; Jehnichen, D.; Häußler, L.; Heinrich, G. Appl. Clay Sci. 2008, 38, 153-164. doi:10.1016/j.clay.2007.03.006

16. Woo, M. A.; Woo Kim, T.; Paek, M.-J.; Ha, H.-W.; Choy, J.-H.; Hwang, S.-J. J. Solid State Chem. 2011, 184, 171-176. doi:10.1016/j.jssc.2010.11.003

17. Iyi, N.; Ebina, Y.; Sasaki, T. J. Mater. Chem. 2011, 21, 8085-8095. doi:10.1039/c1jm10733j

18. Rosa, R.; Leonelli, C.; Villa, C.; Priarone, G. J. Microwave Power Electromagn. Energy 2013, 47, 12-23. doi:10.1080/08327823.2013.11689843

19. Carlino, S. Solid State lonics 1997, 98, 73-84. doi:10.1016/s0167-2738(96)00619-4

20. Choi, G.; Yang, J.-H.; Park, G.-Y.; Vinu, A.; Elzatahry, A.; Yo, C. H.; Choy, J.-H. Eur. J. Inorg. Chem. 2015, 2015, 925-930. doi:10.1002/ejic.201403115

21. Kang, N.-J.; Wang, D.-Y. J. Mater. Chem. A 2013, 1, 11376-11383. doi:10.1039/c3ta12304a

22. Baney, R. H.; Itoh, M.; Sakakibara, A.; Suzuki, T. Chem. Rev. 1995, 95, 1409-1430. doi:10.1021/cr00037a012

23. Cordes, D. B.; Lickiss, P. D.; Rataboul, F. Chem. Rev. 2010, 110, 2081-2173. doi:10.1021/cr900201r

24. Laine, R. M.; Roll, M. F. Macromolecules 2011, 44, 1073-1109. doi:10.1021/ma102360t

25. Fina, A.; Tabuani, D.; Carniato, F.; Frache, A.; Boccaleri, E.; Camino, G. Thermochim. Acta 2006, 440, 36-42. doi:10.1016/j.tca.2005.10.006

26. Feher, F. J.; Wyndham, K. D.; Soulivong D, N. F. J. Chem. Soc., Dalton Trans. 1999, 1491-1497. doi:10.1039/a807302c

27. Cai, H.; Xu, K.; Liu, X.; Fu, Z.; Chen, M. Dalton Trans. 2012, 41, 6919-6921. doi:10.1039/c2dt30378g

28. Gravel, M.-C.; Laine, R. M. Polym. Prepr. (Am. Chem. Soc., Div. Polym. Chem.) 1997, 38 , 155-156.

29. Feher, F. J.; Wyndham, K. D. Chem. Commun. 1998, 323-324. doi:10.1039/a707140j

30. Gravel, M.-C.; Zhang, C.; Dinderman, M.; Laine, R. M. Appl. Organomet. Chem. 1999, 13, 329-336. doi:10.1002/(sici)1099-0739(199904)13:4<329::aid-aoc870>3.0.co;2-v

31. Chen, S.; Mao, M.; Liu, X.; Hong, S.; Lu, Z.; Sang, S.; Liu, K.; Liu, H. J. Mater. Chem. A 2016, 4, 4877-4881. doi:10.1039/c6ta00842a

32. Wilson, O. C.; Olorunyolemi, T.; Jaworski, A.; Borum, L.; Young, D.; Siriwat, A.; Dickens, E.; Oriakhi, C.; Lerner, M. Appl. Clay Sci. 1999, 15, 265-279. doi:10.1016/s0169-1317(99)00023-x

33. Meyn, M.; Beneke, K.; Lagaly, G. Inorg. Chem. 1990, 29, 5201-5207. doi:10.1021/ic00351a013

34. Wang, L.; Lü, Z.; Li, F.; Duan, X. Ind. Eng. Chem. Res. 2008, 47, 7211-7218. doi:10.1021/ie800609c

35. Xu, J.; Song, Y.; Tan, Q.; Jiang, L. J. Mater. Sci. 2017, 52, 5908-5916. doi:10.1007/s10853-017-0826-y

36. Ozawa, T. Bull. Chem. Soc. Jpn. 1965, 38, 1881-1886. doi:10.1246/bcsj.38.1881

37. Joseph, H. F.; Wall, L. A. J. Res. Natl. Bur. Stand., Sect. A 1966, 70A, 487-523. doi:10.6028/jres.070a.043

38. Tanaka, K.; Inafuku, K.; Adachi, S.; Chujo, Y. Macromolecules 2009, 42, 3489-3492. doi:10.1021/ma900113j 


\section{License and Terms}

This is an Open Access article under the terms of the Creative Commons Attribution License (http://creativecommons.org/licenses/by/4.0). Please note that the reuse, redistribution and reproduction in particular requires that the authors and source are credited.

The license is subject to the Beilstein Journal of Nanotechnology terms and conditions:

(https://www.beilstein-journals.org/bjnano)

The definitive version of this article is the electronic one which can be found at:

doi:10.3762/bjnano.9.284 